\title{
Cohort Fertility: A Comparison of the Results of the Official Birth Statistics and of the Microcensus Survey 2008
}

\section{Olga Pötzsch}

\begin{abstract}
Data are available for the first time for the year under report 2008 on the biological number of children of women from the comprehensive Microcensus sample. Previously, only the ongoing birth statistics provided information on cohort fertility as a total fertility rate of the synthetic female cohorts. Since both benchmarks bear different types of insecurity, a comparison is to provide important information on the quality of these indicators.

This article shows that the average number of children per woman in the dataset of the Microcensus 2008 and the cohort fertility rate in the birth statistics show a highly similar course of cohort fertility. Whilst the agreement for the female cohorts in the new Länder (former GDR without Berlin East) and in Germany as a whole is almost complete, the values in the old Länder (Western Germany without Berlin West) are further apart. A major cause of this evidently lies in the high proportion of female immigrants in the old Länder. Some of the women who immigrated into the former territory of Federal Republic already gave birth to their children before entering Germany. These births could not be taken into account in the ongoing birth statistics, whilst the Microcensus provided information on all children born, regardless of where they were born. These survey-related deviations can be largely reduced if the comparison with the cohort fertility rate of the birth statistics is based not on the average number of children of all women, but only on the number of children of women who were born in Germany or who immigrated below the age of 26. The share of female migrants was low in the new Länder and did not impact cohort fertility. All in all, the comparison showed that both sets of statistics provide data with a good degree of concurrence on the fertility of the birth years from 1933 to 1992 for Germany as a whole, as well as for the old and the new Länder. This makes it possible to carry out detailed analyses of fertility in relation to comprehensive socioeconomic characteristics of the Microcensus.
\end{abstract}

Keywords: Fertility · TFR $\cdot$ number of children $\cdot$ childlessness $\cdot$ Microcensus · statistic of births $\cdot$ migration experience 


\section{Introduction}

The total fertility rate is customarily calculated in official statistics on the basis of the data of the fertility statistics. Both the total fertility rates of the calendar years and those of the cohorts are so-called synthetic indicators: The average number of children per woman is calculated by ascertaining the number of births and the number of women independently and then linking them arithmetically per calendar year or per cohort.

The second method for recording the births of the women's cohorts is to survey the women themselves. This makes it possible to ascertain an average number of children per woman in a fully-integrated manner which relates to real cohorts of women who are currently alive and comes from one source of data. In addition to the average number of children, such statistics also reveal the spread of women according to the number of children. The first official survey of women on the number of children born in the unified Germany was carried out in 2006 in the framework of the special survey entitled "Births in Germany". In addition to the data on the extent of childlessness and on the number of mothers' children, this study also provided detailed data on the age of the women when their children were born (Pötzsch) Sommer 2009). Data are now available for the first time from the large Microcensus ${ }^{1}$ sample for the year under report 2008 relating to the number of women's biological children.

A comparison of the total fertility rate of the synthetic women's cohorts from the ongoing fertility statistics with the average number of children from the Microcensus 2008 can provide important information on the quality of both indicators. If agreement is good, or if any deviations present can be reasoned, then both sets of statistics are coherent, they may complement one another and be regarded in conjunction. If the results deviate considerably from one another, the causes of the deviations must be studied. Complete agreement between the results cannot be expected because of the conceptual differences between the two sets of statistics: The information from the fertility statistics reflects the relationship between the number of births and the number of women alive at the time of these births. By contrast, retrospective information concerning the women of the corresponding cohorts living in Germany in 2008 is included in the Microcensus survey observed here. Since the totality of women has changed over the years and decades as a result of mortality and migration, the current "stocktake" may deviate from the values calculated in the fertility statistics. Over and above this, the information obtained from a sample on the number of children may contain both random and systematic errors. These too must be taken into account when interpreting the result.

The goal of the present article is to compare the available fertility rates from the ongoing fertility statistics (as per 2008) and from the Microcensus 2008 with one

1 The microcensus is the most comprehensive European household survey with a sample size of $1 \%$ of the population and varied information on personal data and private households. 
another and to indicate particularities, strengths and weaknesses in the two indicators. Subsequently, first of all the data basis, the quality of the data and the territorial structure used will be discussed. Then the fertility measures of the women's cohorts from the fertility statistics on the one hand and from the Microcensus survey 2008 on the other hand will be compared with one another. Separate information will be provided here on the women's cohorts in the former territory of Federal Republic (old Länder), in the new Länder and in Germany as a whole. The results of the fertility statistics will be referred to as cohort fertility rates (or CFR) and the results of the Microcensus as the average number of children.

\section{Sources and quality of the data}

\section{Fertility statistics}

The first source of data for ascertaining the fertility rates in the fertility statistics are the reports on a birth, which are transmitted by the registry offices to the official statistics. There, they are examined and totalled to form a national result. This is an ongoing total survey. The quality of these so-called secondary data on births, which are based on administrative information, is regarded as being high (Federal Statistical Office: Qualitätsbericht "Fortschreibung"). This also applies with certain restrictions to data on births in the former GDR.

Secondly, the fertility rates are calculated on the basis of the number of women who are ascertained in the context of the ongoing updates of the size of the population. The annual updates of the population by gender, as well as by birth years, takes place with the aid of the results of the statistics of births and deaths, as well as of the statistics on migration. The population data from 1987 consist of extrapolated figures based on the census of 25 May 1987. In the new Länder and East Berlin population counts rely on updates of an extract from the former Central Population Register from 3rd of October 1990. The last census was accomplished in the GDR in 1981, thus almost thirty years ago. Some recalculations were carried out after reunification in October 1990 in the interest of methodical standardisation, including that the average population used to calculate the fertility rates was recalculated (Federal Statistical Office 1996). The population updating has been carried out according to the same rules as in the former territory of Federal Republic since 1990.

The quality of the population updating reduces as the time since the last census increases. The number of women used in the denominator of the formula therefore constitutes an uncertainty factor in calculating the fertility rates.

\section{Microcensus}

Until the survey that was carried out in 2008, the Microcensus exclusively collected information regarding the children living in the household. No distinction was made here between biological and non-biological children, and children living outside the household were not considered. The Microcensus Act (Mikrozensusgesetz) and the 
Population Statistics Act (Bevölkerungsstatistikgesetz) were reformed in autumn 2007 (Federal Law Gazette [BGBI] 2007 Part I No. 55). The characteristic "No. of biological children" was introduced in the programme of the Microcensus, which may be surveyed on a voluntary basis every four years. All 15- to 75-year-old women were surveyed for the first time in the Microcensus survey 2008 as to the number of children born. The next survey will take place as part of the Microcensus 2012.

The most important results on the spread of women by number of children, on the level of childlessness, as well as on the regional and sociodemographic characteristics of childless women and on mothers, have already been published (Federal Statistical Office 2009; Dorbritz 2010). The level of cohort fertility is now observed in this article, emerging from the information provided by the respondents.

In order to ascertain fertility standards that are comparable with the cohort numbers from the official fertility statistics on the basis of the data of the Microcensus 2008, the following distinctions need to be made in the Microcensus dataset:

1) The female population at the main place of residence is observed.

2) The information on biological children is available in the dataset of the Microcensus 2008 for women aged from 15 to 75 . Since the calculation of the average number of children refers to the birth cohorts of women, only the cohorts 1933 to 1992 , which were covered in their entirety, can be considered for this who were aged from 16 to 75 in 2008.

The quality of the Microcensus data obtained from a stratified cluster sample (Esser et al. 1989; Lotze/Breiholz 2002) depends on both sample-related and nonsample-related errors. The precision of the information, which is provided on a voluntary basis, is particularly impaired by the characteristics of the missing responses.

There is no obligation to provide information as to the question regarding the birth of children. It was answered by $89 \%$ of 15- to 75-year-old women in the 2008 Microcensus survey. Indications of possible systematic missing responses led to the application of a two-tiered imputation procedure. This made it possible to minimise systematic distortions in the results on maternity and childlessness (Federal Statistical Office 2009).

The coincidence-related sampling error cannot be precisely calculated in the Microcensus, but its amount can be estimated in quantitative terms. "The standard error is used as an estimated value which is calculated from the individual data of the sample. If the sample is sufficiently large, one may presume a probability of roughly $68 \%$ that the respective value of the population lies within the range of the simple standard error and a probability of approx. $95 \%$ that it lies within the field of twice the standard error around the extrapolated value." (Federal Statistical Office: Qualitätsbericht "Mikrozensus"). 
The error calculation ${ }^{2}$ carried out for the average number of children at the level of five-year groups indicates a high degree of reliability of the values both for Germany as a whole and for the old and the new Länder (Annex Table 1). Only in the youngest age group of Eastern German women aged from 16 to 19 does the relative standard error exceed $15 \%$. A heterogeneous image however emerges at the level of the Federal Länder. In the Land-related evaluations, it is hence recommended in particular for the smaller Länder to take account of the relative and absolute sampling errors.

Only valid cases were evaluated in order to calculate the average number of children: These are, firstly, women who stated that they had not given birth to a child, and secondly mothers who made a statement regarding the number of children to whom they had given birth. All statements refer to the extrapolated results.

\section{Territorial structure}

The cohort fertility rates (CFR) are available for Germany as a whole, as well as - up to 2000 - for the former Federal territory (including Berlin West) and the new Länder including Berlin East. After the Berlin territorial reform which took place in 2001, it is no longer possible to show West and East Berlin in the old delimitation. For this reason, Berlin is considered as a whole at the earliest from 1990, the year of German Unity, and at the latest from the year under report 2001, and, depending on the situation as regards the data and on content-related preferences, is either attributed to one of the two territorial parts or not considered in either of the two territorial parts. Since the differences in birth developments between Eastern and Western Germany are most visible when the two territories are regarded without Berlin, the earliest possible time was selected in this article for the CFR (Annex Tab. 3):

1) Germany;

2) former territory of Federal Republic: until the year under report 1989, including Berlin West, from the year under report 1990, not including Berlin West (= old Federal Länder not incl. Berlin).

3) New Länder:

until the year under report 1989: former GDR including Berlin East, from the year under report 1990: new Länder not incl. Berlin.

The average number of children in the Microcensus refers to the following territorial structures:

1) Germany

2) old Federal Länder not incl. Berlin.

3) new Länder not incl. Berlin.

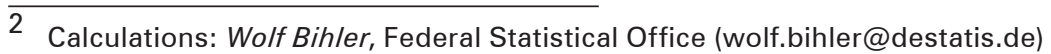




\section{Comparison of the results of the fertility statistics and of the Microcensus}

The results of the Microcensus 2008 do not provide any other picture of the development in fertility in Germany than the data from the fertility statistics (Fig. 1). Both the periods of the rapid drop in the final number of children per woman between the cohorts 1933 and 1945, of the ensuing slower fall approximately until the cohort of 1954 , and the phase of relative stability until the women's cohorts which were born at the end of the 1950s, are reproduced in a similar manner by both benchmarks.

If one takes a closer look, however, it is possible to distinguish between fields in which the deviations are somewhat larger and - even more importantly - in which the result of the Microcensus is systematically above or below the CFR. These fields are observed separately below for the old and new Länder.

Fig. 1: Total fertility rate of cohorts - Germany

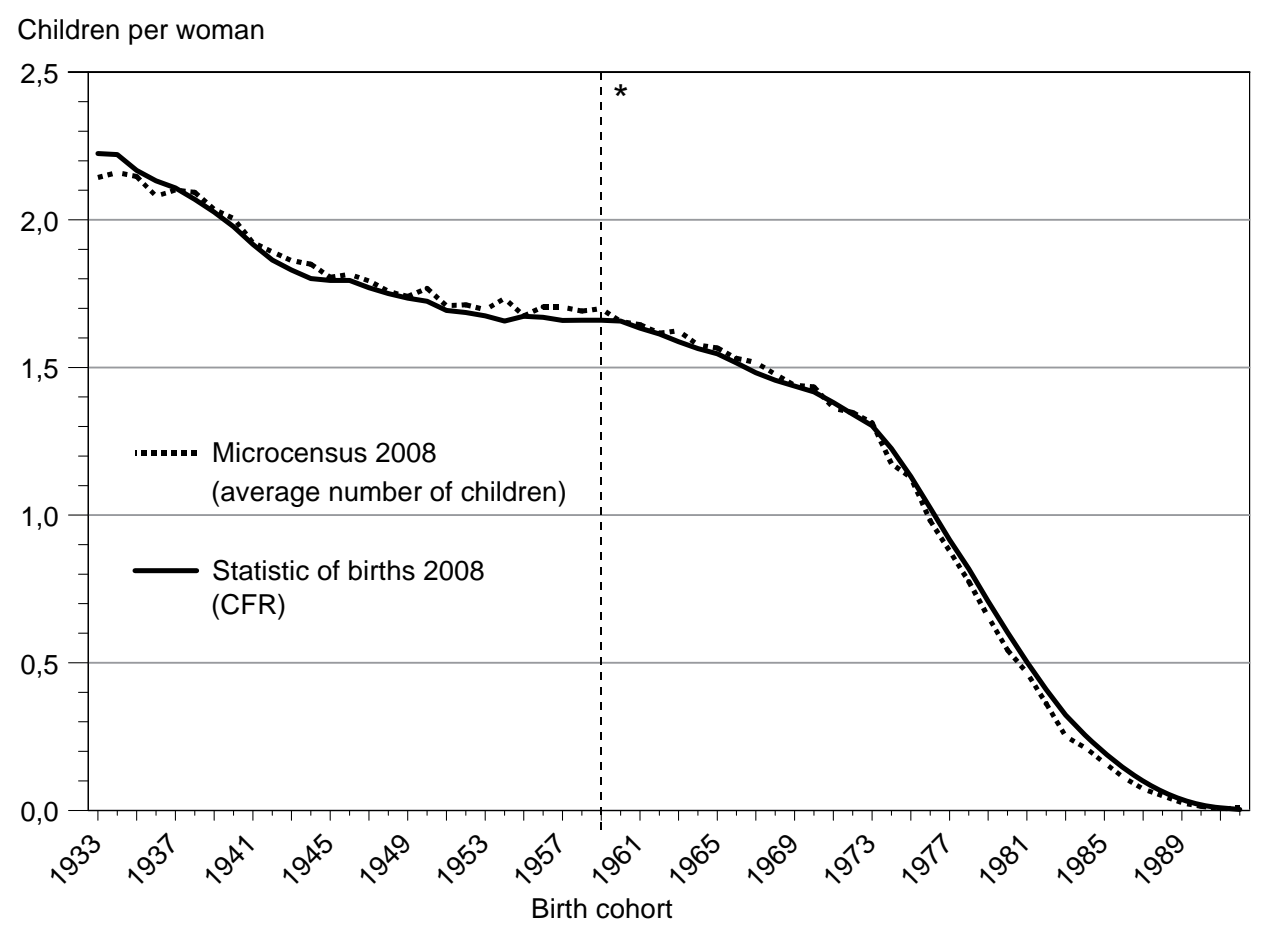

* Until cohort 1959: completed number of children, from cohort 1958: number of children until the respective age.

Source: Federal Statistical Office 


\section{Old Federal Länder}

The average number of children in the former territory of Federal Republic takes a similar course to the CFR (Fig. 2). It does however come to notice that the average number of children with cohorts 1938 to 1968 systematically exceeds the CFR of these cohorts. It remains slightly lower with the younger cohorts from 1976 to 1986 , by contrast. The deviations with the younger cohorts are of little relevance for the evaluation of the fertility level. One may presume a reliable CFR for these cohorts, given that the quality of the population updating is likely to have been hardly impaired for the relatively young women. Imprecise population figures would tend to lead to a lower CFR, and not to the opposite, as is observed with the cohorts 1976 to 1986. A slight underestimation in the Microcensus cannot be ruled out, by contrast.

Much greater significance for the proof of cohort fertility is assumed by the stable negative difference between the CFR and the average number of children in the cohorts from 1938 to 1968 . These deviations cannot be explained by the sampling error alone. On the one hand, due to shortcomings in the population updating,

Fig. 2: Total fertility rate of cohorts - old Federal Länder

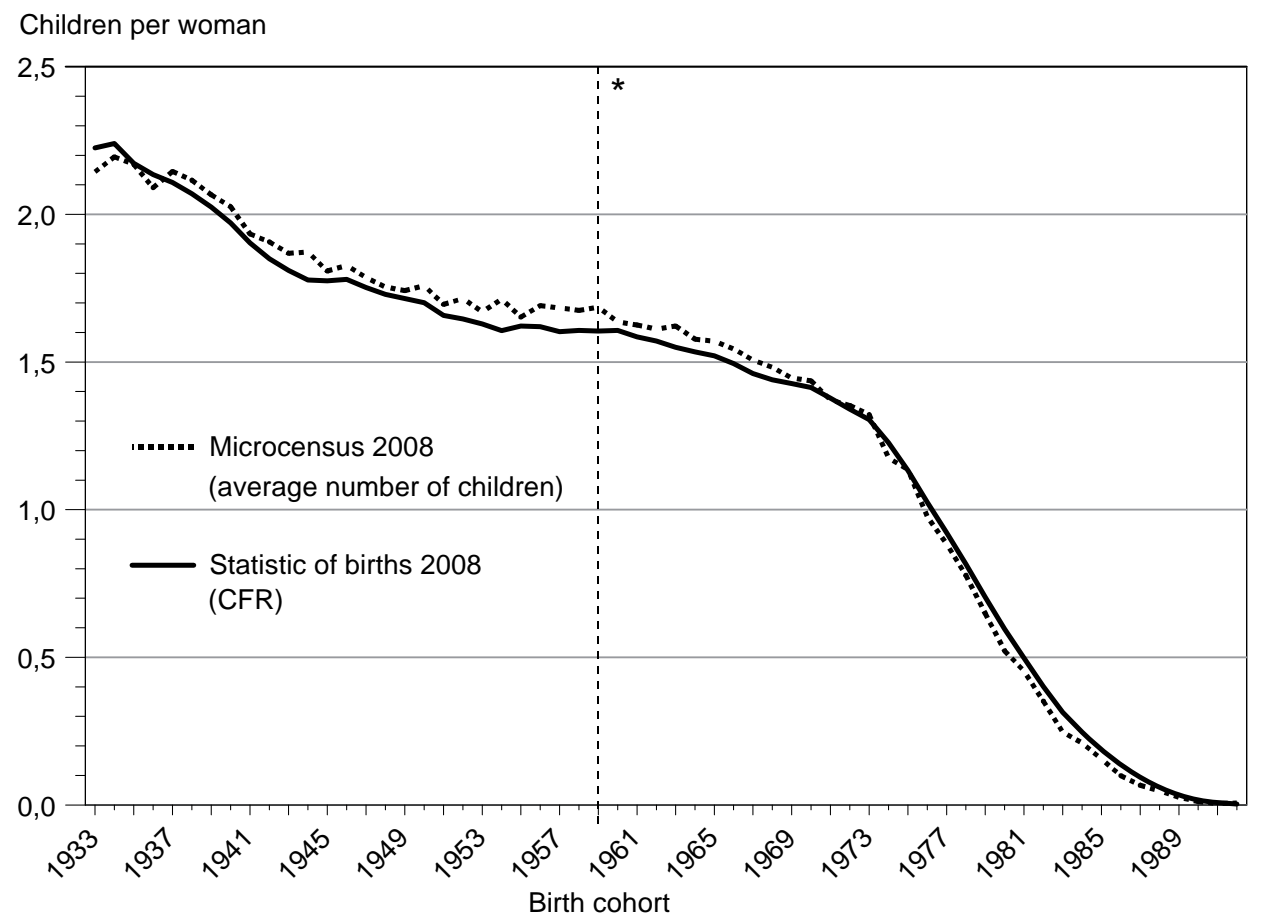

* Until cohort 1959: completed number of children, from cohort 1958: number of children until the respective age.

Source: Federal Statistical Office 
the number of women to which the births are related could be slightly overrated. In this case, however, the CFR would be underestimated. On the other hand, it suggests itself in light of a relatively large share of female migrants in the former Federal territory to suppose that some of the children born to women who migrated to Germany were not reflected in the fertility statistics. By contrast, these women stated the full number of children in the Microcensus survey.

It was possible to verify the latter hypothesis using the Microcensus data. The question was explored as to how the average number of children changes in the Microcensus 2008 if this does not relate to all women, but only to women who were born in Germany or who migrated there in a younger child-bearing age.

An iterative procedure was able to determine the delimitation of the female population in the Microcensus which facilitates optimum agreement of the average number of children and of the CFR. If women were born in Germany, or if they migrated there before the age of 26 , the probability is high that their births were covered by the fertility statistics. As emerges from Figure 3, the deviations between the average number of children and the CFR of these women are much lower with the cohorts 1938 to 1968 .

Fig. 3: Total fertility rate of cohorts - old Federal Länder

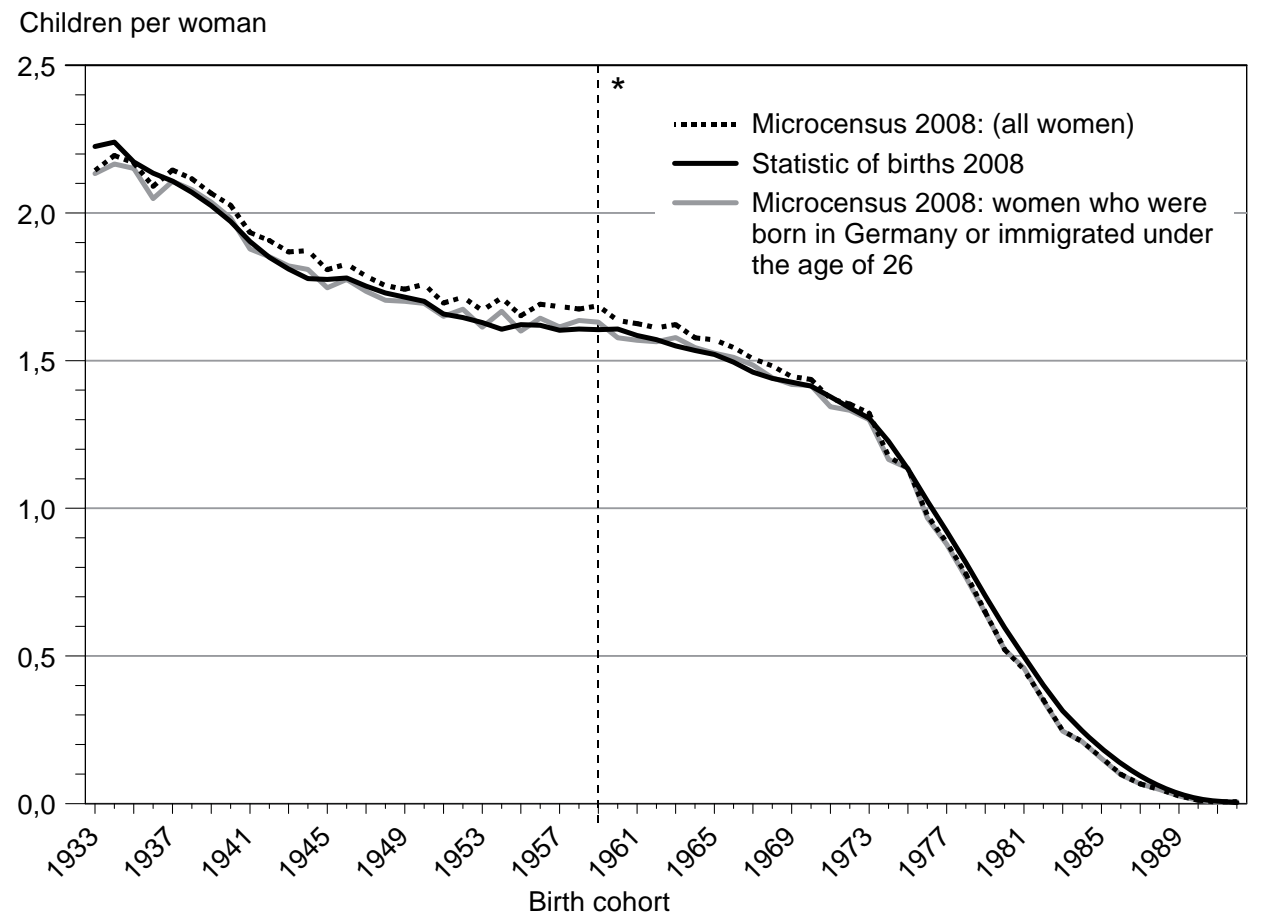

* Until cohort 1959: completed number of children, from cohort 1958: number of children until the respective age.

Source: Federal Statistical Office 
The absolute deviations from the CFR fluctuate if one takes into consideration the entire female population in the Microcensus between 0.02 and 0.11 (the upper value occurs once in the 1954 cohort). When considering women born in Germany and women who immigrated before reaching the age of 26 , the deviations are only -0.03 to +0.06 (Fig. 4).

A similar effect can be achieved if the highest age at which a woman migrated to Germany is selected within the range of 24 and 28 . The differences when compared to the maximum age portrayed here as under the age of 26 are negligible. If the maximum age when migration occurred is selected below this range, the average number of children falls too steeply. If the maximum age is set above the range, the deviations to the CFR are similar to those for all women.

The delimitation of the population of women by migration experience has no impact on the deviations between the two birth measures among younger women in the cohorts 1976 to 1986.

Fig. 4: Absolute deviation of the average number of children (Microcensus 2008) from the CFR (birth statistics) - old Federal Länder

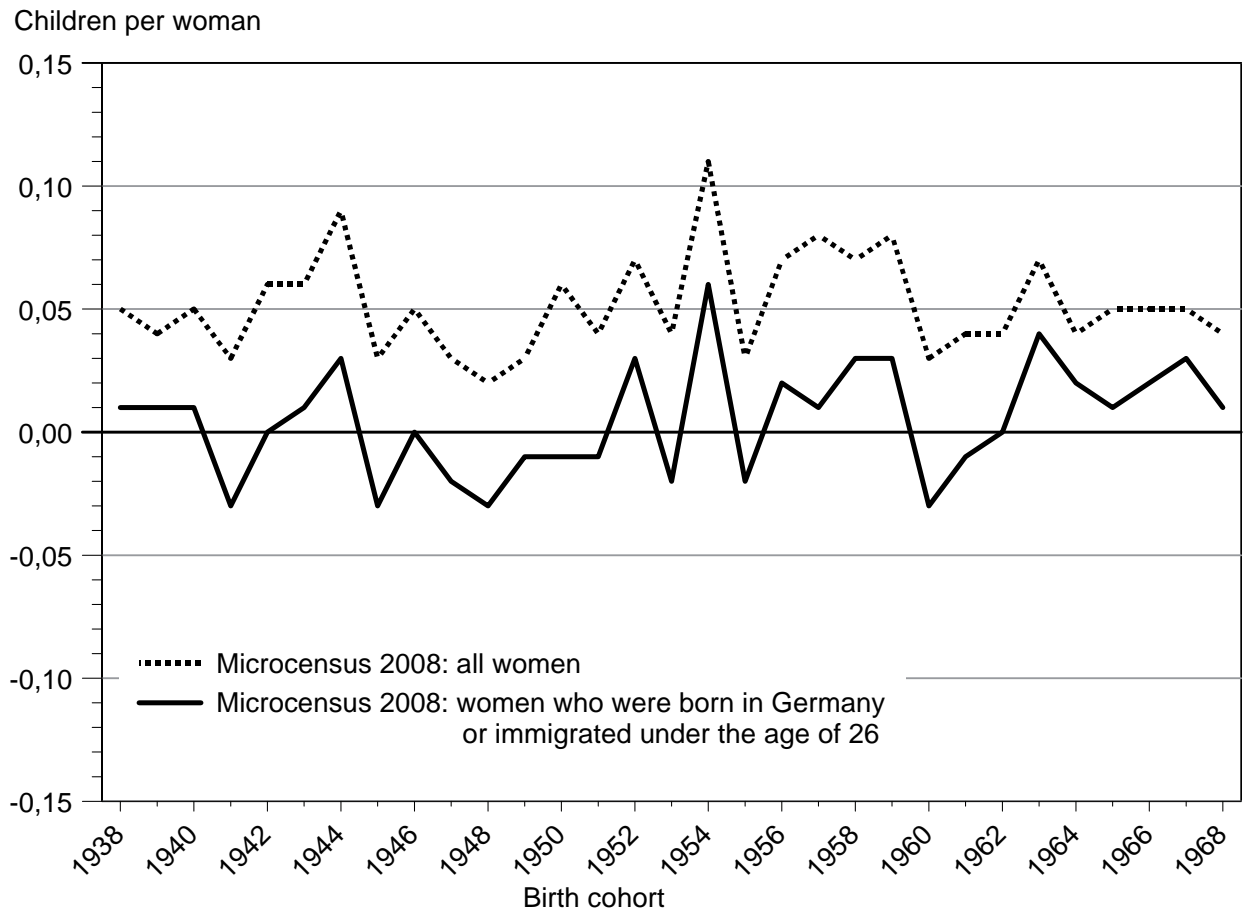

Source: Federal Statistical Office 


\section{Women by number of children with and without consideration of migration experience in the old Federal Länder}

The best approximation of the average number of children in the Microcensus to the cohort fertility rate of the fertility statistics can therefore be reached in the old Länder if not all valid cases are consulted from the dataset of the Microcensus, but only those which refer to women who were born in Germany or who immigrated before the age of 26. The question now arises of when and if so how the distribution of women by number of children differ, which underlie the average number of children of the two female populations: Are we seeing changes by virtue of the delimitation by migration experience above all in the share of women without a child or in the distribution of mothers by the number of their children as well?

We also observed here all valid cases in the old Federal Länder: These are, firstly, women who stated that they had not had children, and secondly mothers stating the number of children which they had had. All statements here refer furthermore to the extrapolated results. The cohorts are collected below into groups of five for a better overview and to make them easier to compare with the results of the Microcensus 2008 that have already been published.

Women who were born in Germany or who immigrated before the age of 26 account for a total of $93 \%$ of all women of birth cohorts 1933 to 1992 . This share differs depending on the number of children which the women have had: It is $97 \%$ among women with no children, and it is $83 \%$ among women with four or more children.

Table 1 contains the absolute and relative distributions of women by the number of children. These show that the distributions of the two populations agree very closely. As was expected, comparably large deviations, which however do not exceed 1.4 percentage points, are recorded in the medium age groups with women without a child and with women with four or more children (Fig. 5).

Depending on the goal pursued by an analysis, it must consequently be weighed up whether the slight shifts in the distribution of women by the number of the children can be accepted. The overall statement however remains unaffected by the selection of the deviations observed here. However, in particular with future time comparisons (the next survey on the number of children in the Microcensus is planned for 2012) it should be ensured that the delimitation of the female population by migration experience may exert an influence on the results and on their interpretation. 


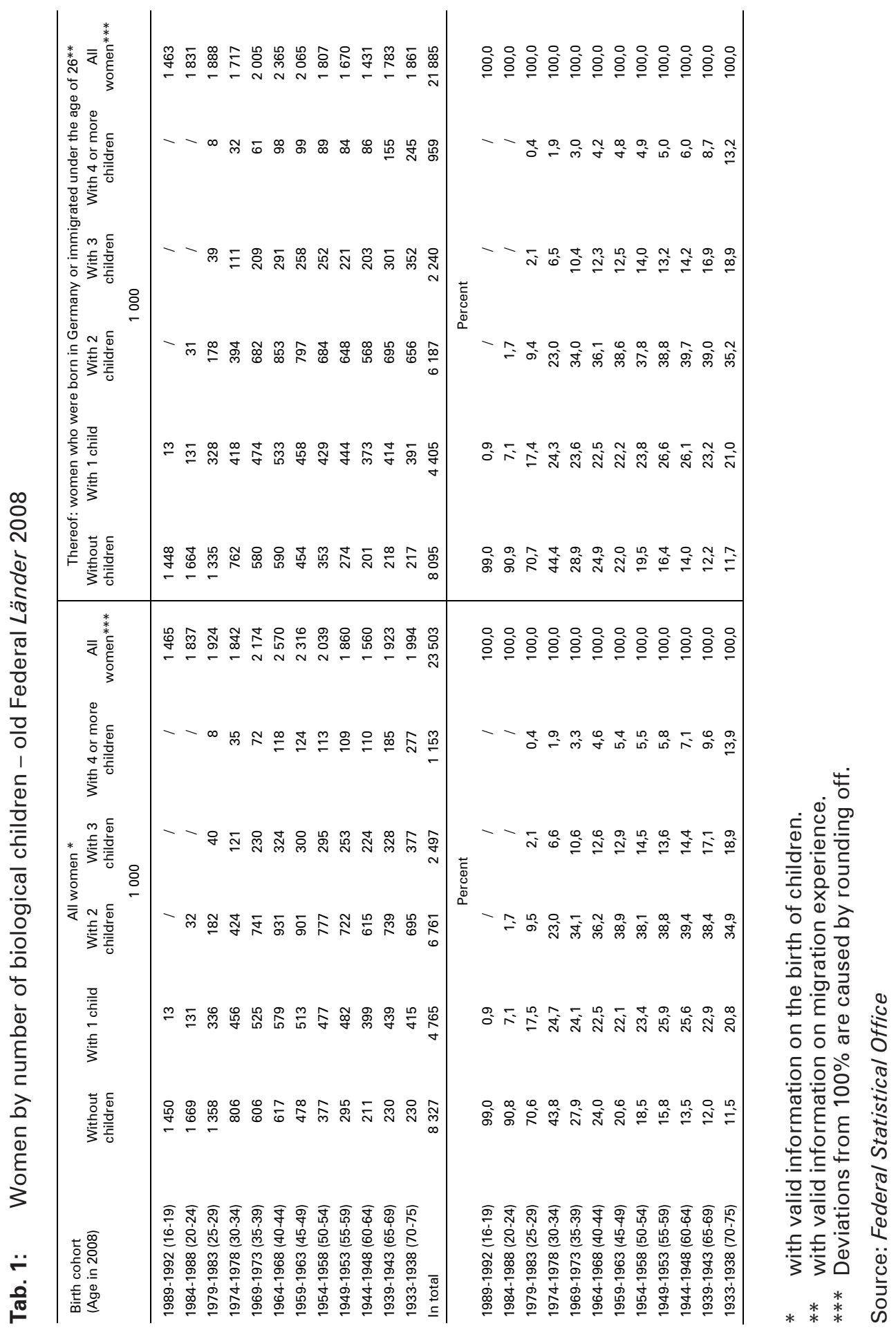


Fig. 5: Relative share of women by number of children: difference between the shares of all women and the shares of women born in Germany or who immigrated before the age of 26 - old Federal Länder 2008

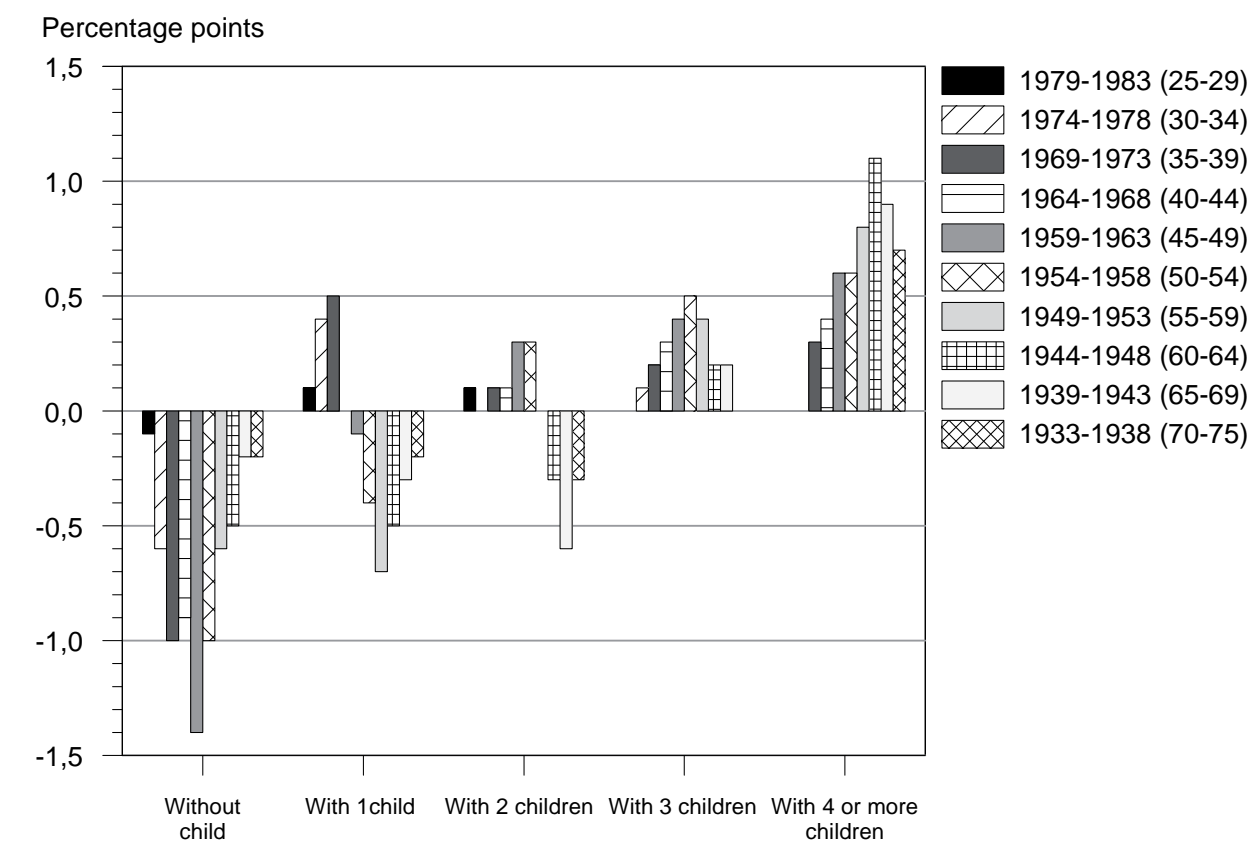

Source: Federal Statistical Office

\section{New Länder}

The two fertility measures agree very well for the women's cohorts in the new Länder. With few exceptions, the deviations are lower than $+/-0.06$. The exceptions are constituted by the cohorts 1967,1970 and 1983. The average number of children in these cohorts deviates from the CFR by $0.08,0.10$ and -0.08 respectively (Fig. 6 ). The share of women with a migration experience is very low in the new Länder, so that the birth conduct is more homogeneous all in all than in the old Länder. The visible fluctuations over the average number of children favour collecting the cohorts into groups of five in the evaluation of the Microcensus results for the new Länder.

\section{Germany}

The average number of children for all women can be used to compare the results of the Microcensus and the fertility statistics for Germany as a whole. It emerges here that the deviations are slighter than with the cohorts in the old Länder. An evaluation of the Microcensus results, for instance in relation to the distribution of the women 
Fig. 6: Total fertility rate of cohorts - new Federal Länder

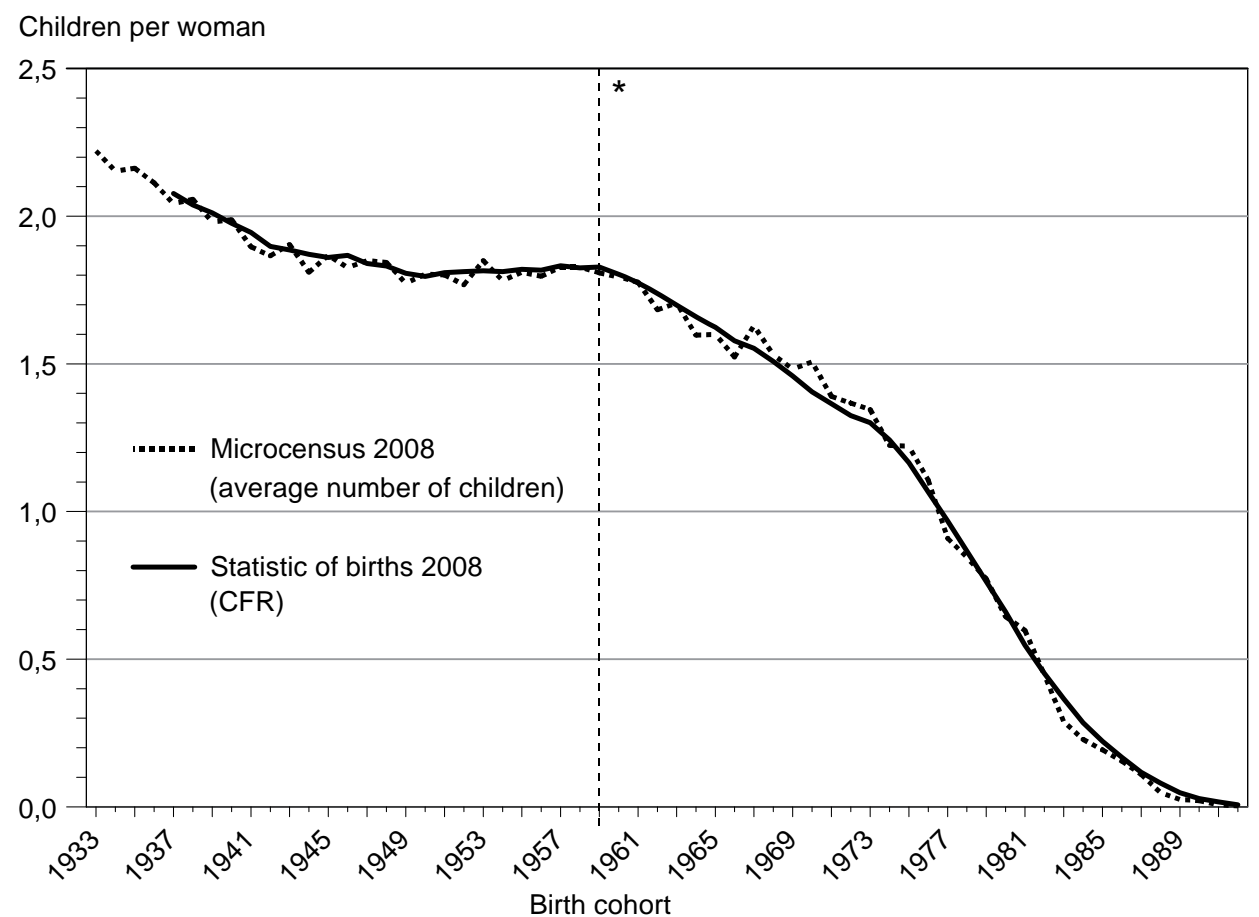

* Until cohort 1959: completed number of children, from cohort 1958: number of children until the respective age.

Source: Federal Statistical Office

by the number of children, would therefore not imply any significant deviations from the CFR in the fertility statistics.

If the evaluations from the Microcensus were related both to Germany as a whole and to the territorial areas, the following delimitation of the female population by migration experience would be preferable: Only women who were born in Germany or who immigrated before reaching the age of 26 would be taken into account with the women's cohorts in the old Länder and in Berlin, and all women would be taken into account with the cohorts in the new Länder. This would bring about a major, necessary correction of the average number of children among the Western German cohorts, as well as a slight improvement in the agreement of the results for Germany (Fig. 3 and 7). 
Fig. 7: Total fertility rate of cohorts - Germany

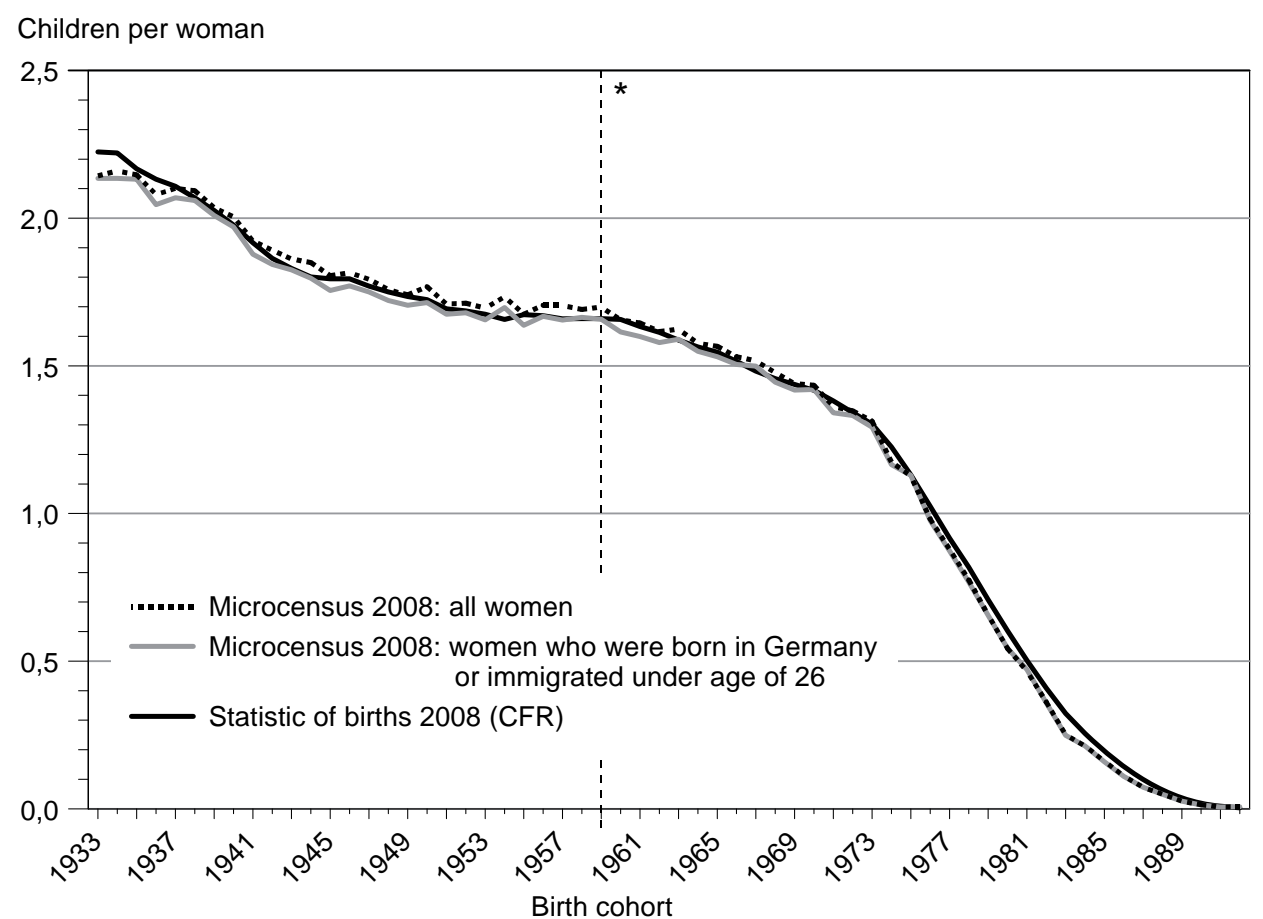

* Until cohort 1959: completed number of children, from cohort 1958: number of children until the respective age.

Source: Federal Statistical Office

\section{Conclusions}

In summing up, it can be stated that the average number of children per woman in the dataset of the Microcensus 2008 and the cohort fertility rate (CFR) in the fertility statistics show a very similar course to cohort fertility. Both sets of statistics hence provide comparable data for the birth cohorts from 1933 to 1992 which can be analysed in context. ${ }^{3} \mathrm{~A}$ few particularities should however be observed when carrying out further evaluations of the Microcensus 2008, and when interpreting the results:

1) The average number of children with the younger cohorts in the Microcensus is somewhat lower than the CFR in the fertility statistics. These deviations oc-

3 Both the trends in age-specific cohort fertility from the fertility statistics and the spread of women by the number of children from the Microcensus 2008 was taken into account in the presumptions of future birth developments in the 12th coordinated population forecast (Pötzsch 2010). 
cur more frequently among the Western German cohorts than among women in the new Länder. One should presume with these deviations that the CFR for the young women's cohorts is of a higher quality. Because the information on children is provided on a voluntary basis in the Microcensus, it is not possible to rule out that a small number of younger women may not be recorded.

2) The average number of children in the cohorts 1938 to 1968 tends to be higher in the old Länder than the CFR in the fertility statistics. The main cause of these differences is obviously that a relatively large share of women migrating to the former territory of Federal Republic of Germany had already had children abroad. These births are not included in the fertility statistics, whilst information was provided in the Microcensus on all children born, regardless of their place of birth. These survey-related deviations can be largely reduced if, for the comparison with the CFR of the fertility statistics, not the average number of children of all women, but only the number of children of women born in Germany or migrating before reaching the age of 26 is used.

3) This delimitation of the Western German population of women by their migration experience leads to marginal changes in the distribution of women by the number of children. The share of women without a child is slightly higher among women born in Germany or migrating before reaching the age of 26, and the share of mothers with four or more children is slightly lower than the corresponding share among all women.

\section{References}

Dorbritz, Jürgen, 2010: Kinderzahlen und Lebensformen im West-Ost-Vergleich - Ergebnisse des Mikrozensus 2008. In: Bevölkerungsforschung Aktuell 31,1. Wiesbaden: BiB

Esser, Hartmut; Grohmann, Heinz; Müller, Walter; Schäffer, Karl-August, 1989: Mikrozensus im Wandel. Untersuchungen und Empfehlungen zur inhaltlichen und methodischen Gestaltung. In: Statistisches Bundeamt (Ed.): Forum der Bundesstatistik. Stuttgart

$B G B I$, 2007: Gesetz zur Änderung des Mikrozensusgesetzes 2005 und des Bevölkerungsstatistikgesetzes vom 30. Oktober 2007, BGBI Jahrgang 2007 Teil I Nr. 55

Federal Statistical Office, 1996: Sonderreihe mit Beiträgen für das Gebiet der ehemaligen DDR 28: 9, 54

Federal Statistical Office, 2009a: Imputation von Werten bei fehlenden Angaben zur Mutterschaft und zur Zahl der geborenen Kinder im Mikrozensus 2008 - Arbeitsbericht. Die Unterlage kann angefordert werden unter: mikrozensus@destatis.de

Federal Statistical Office, 2009b: Mikrozensus 2008 - Neue Daten zur Kinderlosigkeit in Deutschland; Online: destatis.de > Bevölkerung $>$ Geburten und Sterbefälle $>\mathrm{Ge}$ burten und Kinderlosigkeit in Deutschland

Federal Statistical Office: Qualitätsberichte online: destatis.de > Publikationen > Qualitätsberichte > Bevölkerung

Lotze, Sabine; Breiholz, Holger, 2002: Zum neuen Erhebungsdesign des Mikrozensus. In: Wirtschaft und Statistik 5. Statistisches Bundesamt: 359-366 
Pötzsch, Olga; Sommer, Bettina, 2009: Generatives Verhalten der Frauenkohorten im langfristigen Vergleich - Ergebnisse der laufenden Statistik der Geburten und der Erhebung "Geburten in Deutschland". In: Wirtschaft und Statistik 5. Statistisches Bundesamt: $377-396$

Pötzsch, Olga, 2010: Annahmen zur Geburtenentwicklung in der 12. koordinierten Bevölkerungsvorausberechnung. In: Wirtschaft und Statistik 1. Statistisches Bundesamt: $29-40$

Translated from the original text by the Federal Institute for Population Research, for information only. The authorised original article in German is available under the title "Kohortenfertilität: Ein Vergleich der Ergebnisse der amtlichen Geburtenstatistik und der Mikrozensuserhebung 2008", DOI 10.4232/10.CPOS-2010-05de or URN urn:nbn:de:bib-cpos-2010-05de4, at http://www.comparativepopulationstudies.de.

Olga Pötzsch ( $₫)$, Statistisches Bundesamt, Gustav-Stresemann-Ring 11, 65189 Wiesbaden, Germany. E-Mail: olga.poetzsch@destatis.de,

URL: http://www.destatis.de 


\section{Annex}

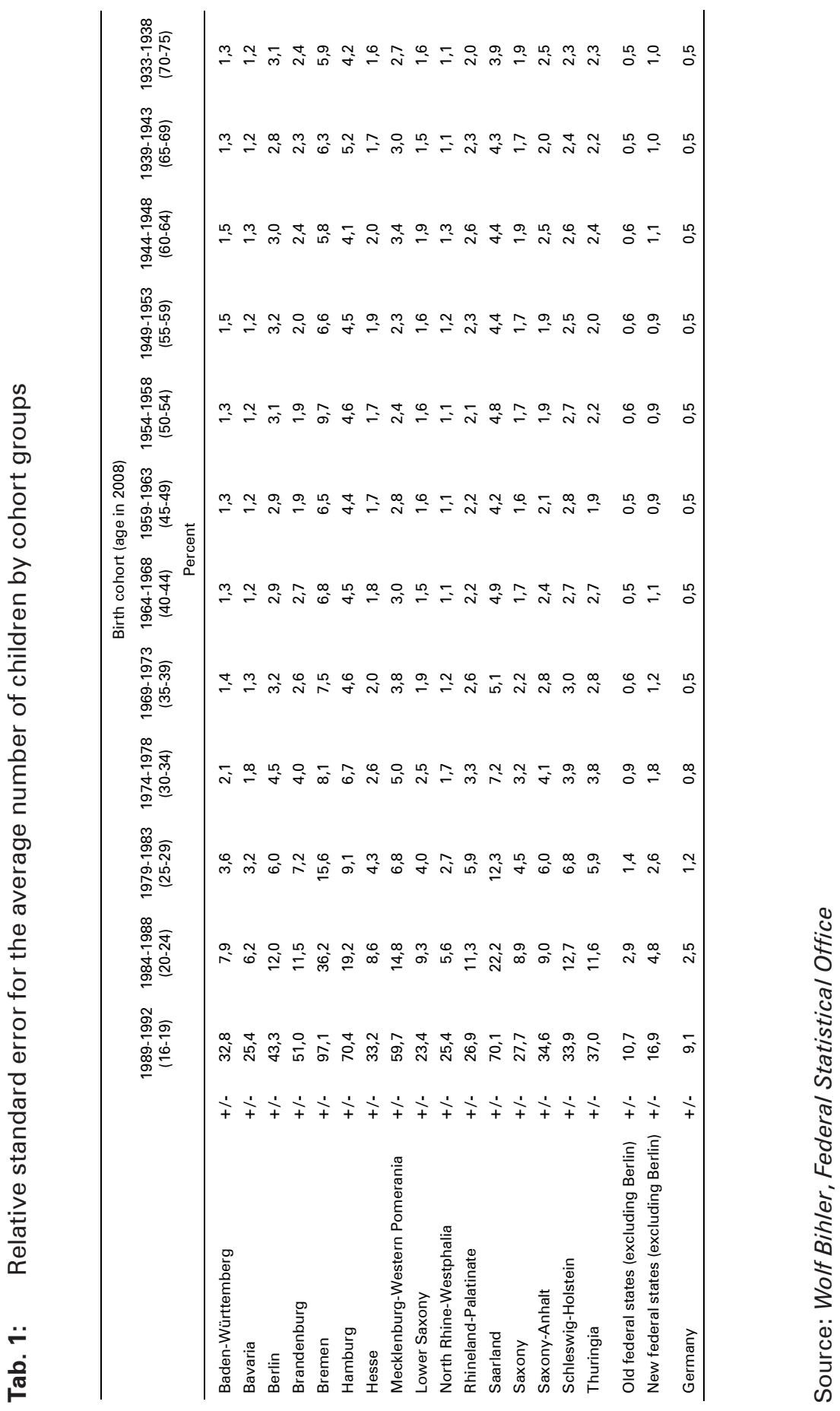




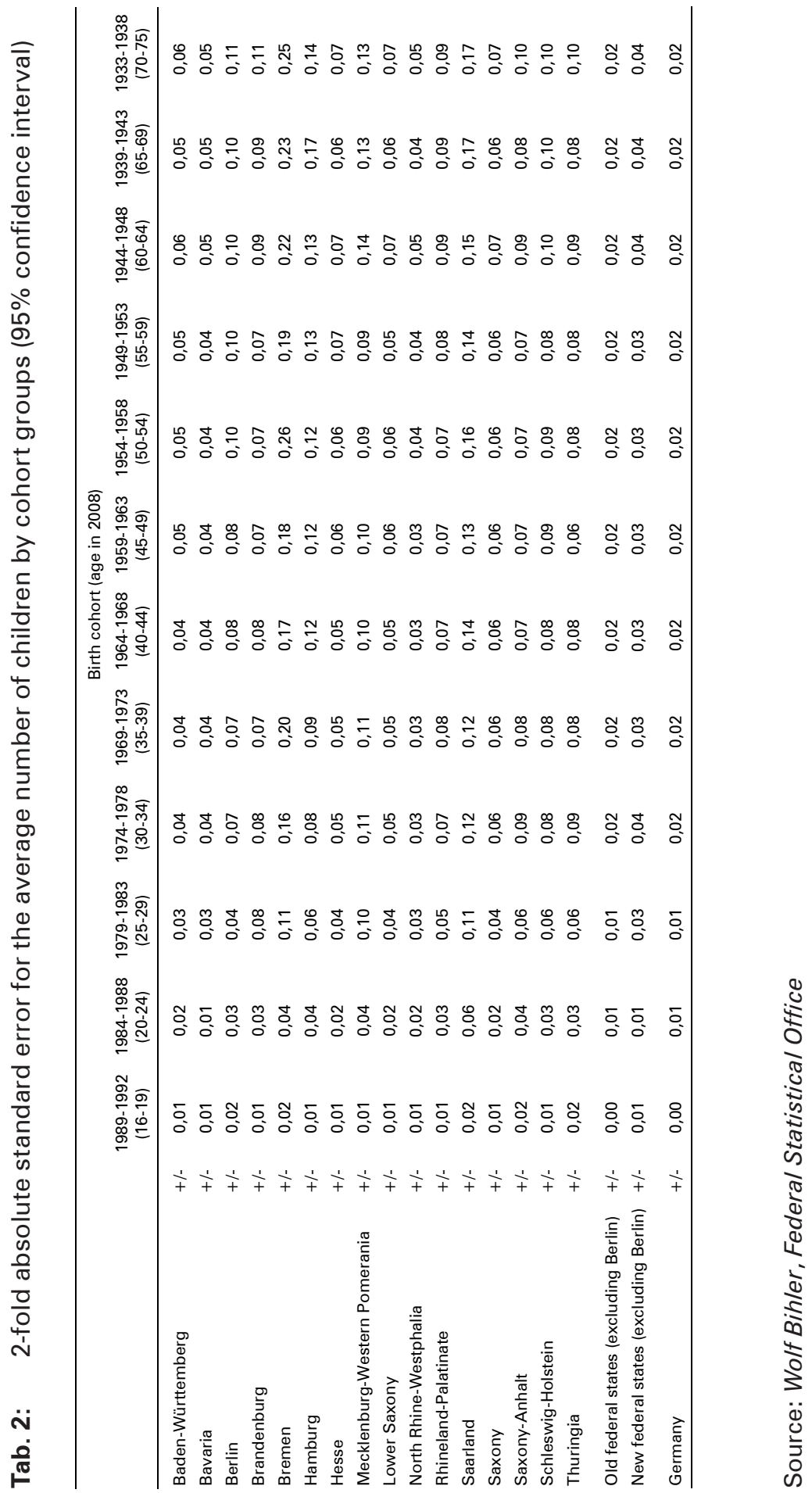


Tab. 3: Average number of children (Microcensus) and total fertility rate of female cohorts (birth statistics) 2008

\begin{tabular}{|c|c|c|c|c|c|c|c|c|}
\hline \multirow{5}{*}{ Birth cohort } & \multicolumn{3}{|c|}{ Microcensus } & \multicolumn{5}{|c|}{ Statistic of births } \\
\hline & \multirow[t]{3}{*}{ Germany* } & \multirow{2}{*}{ Old federal states * } & \multirow[t]{2}{*}{ New federal states } & \multirow[t]{3}{*}{ Germany } & \multirow{2}{*}{$\begin{array}{l}\text { Old federal } \\
\text { states }\end{array}$} & \multirow{3}{*}{$\begin{array}{l}\text { New federal } \\
\text { states } \\
\text { lin/ East Berlin } \\
990\end{array}$} & \multicolumn{2}{|c|}{ Nachrichtlich: } \\
\hline & & & & & & & Old federal states & New federal states \\
\hline & & \multicolumn{2}{|c|}{ Excluding Berlin } & & \multicolumn{3}{|c|}{$\begin{array}{l}\text { excluding West Berlin/ East Berlin } \quad \text { excluding West Berlin/ East Berlin } \\
\text { from } 1990\end{array}$} & \\
\hline & Average & number of children $p$ & er 1000 women & & & born children pe & 1000 women & \\
\hline 1933 & 2.135 & 2.133 & 2.221 & 2.224 & 2.225 & 1 & 2.225 & 1 \\
\hline 1934 & 2.135 & 2.166 & 2.153 & 2.221 & 2.240 & I & 2.240 & I \\
\hline 1935 & 2.132 & 2.151 & 2.162 & 2.167 & 2.173 & 1 & 2.173 & i \\
\hline 1936 & 2.046 & 2.049 & 2.113 & 2.132 & 2.135 & 1 & 2.135 & 1 \\
\hline 1937 & 2.069 & 2.107 & 2.042 & 2.108 & 2.108 & 2.077 & 2.108 & 2.077 \\
\hline 1938 & 2.060 & 2.079 & 2.057 & 2.069 & 2.070 & 2.038 & 2.070 & 2.038 \\
\hline 1939 & 2.009 & 2.037 & 1.980 & 2.026 & 2.025 & 2.011 & 2.025 & 2.011 \\
\hline 1940 & 1.970 & 1.983 & 1.988 & 1.977 & 1.971 & 1.976 & 1.971 & 1.976 \\
\hline 1941 & 1.878 & 1.878 & 1.896 & 1.917 & 1.903 & 1.945 & 1.903 & 1.945 \\
\hline 1942 & 1.843 & 1.852 & 1.866 & 1.864 & 1.850 & 1.898 & 1.850 & 1.898 \\
\hline 1943 & 1.825 & 1.821 & 1.904 & 1.830 & 1.810 & 1.886 & 1.810 & 1.886 \\
\hline 1944 & 1.797 & 1.809 & 1.810 & 1.801 & 1.778 & 1.871 & 1.778 & 1.871 \\
\hline 1945 & 1.755 & 1.747 & 1.867 & 1.795 & 1.775 & 1.860 & 1.775 & 1.860 \\
\hline 1946 & 1.771 & 1.775 & 1.826 & 1.795 & 1.780 & 1.867 & 1.780 & 1.867 \\
\hline 1947 & 1.750 & 1.735 & 1.850 & 1.770 & 1.752 & 1.840 & 1.752 & 1.839 \\
\hline 1948 & 1.721 & 1.704 & 1.843 & 1.750 & 1.729 & 1.831 & 1.729 & 1.831 \\
\hline 1949 & 1.705 & 1.701 & 1.773 & 1.735 & 1.715 & 1.807 & 1.715 & 1.806 \\
\hline 1950 & 1.714 & 1.694 & 1.804 & 1.724 & 1.701 & 1.796 & 1.701 & 1.795 \\
\hline 1951 & 1.675 & 1.650 & 1.801 & 1.693 & 1.658 & 1.809 & 1.658 & 1.807 \\
\hline 1952 & 1.680 & 1.674 & 1.768 & 1.686 & 1.646 & 1.812 & 1.647 & 1.810 \\
\hline 1953 & 1.656 & 1.613 & 1.850 & 1.675 & 1.629 & 1.815 & 1.629 & 1.812 \\
\hline 1954 & 1.697 & 1.667 & 1.782 & 1.657 & 1.606 & 1.812 & 1.606 & 1.809 \\
\hline 1955 & 1.637 & 1.600 & 1.810 & 1.673 & 1.622 & 1.820 & 1.622 & 1.816 \\
\hline 1956 & 1.668 & 1.644 & 1.797 & 1.670 & 1.620 & 1.817 & 1.619 & 1.813 \\
\hline 1957 & 1.655 & 1.614 & 1.827 & 1.659 & 1.603 & 1.832 & 1.603 & 1.825 \\
\hline 1958 & 1.664 & 1.636 & 1.827 & 1.660 & 1.607 & 1.825 & 1.605 & 1.821 \\
\hline 1959 & 1.658 & 1.630 & 1.808 & 1.660 & 1.605 & 1.828 & 1.603 & 1.819 \\
\hline 1960 & 1.615 & 1.577 & 1.794 & 1.657 & 1.607 & 1.803 & 1.603 & 1.795 \\
\hline 1961 & 1.599 & 1.569 & 1.776 & 1.633 & 1.585 & 1.774 & 1.580 & 1.762 \\
\hline 1962 & 1.579 & 1.564 & 1.683 & 1.613 & 1.571 & 1.738 & 1.564 & 1.723 \\
\hline 1963 & 1.590 & 1.578 & 1.706 & 1.587 & 1.550 & 1.699 & 1.542 & 1.679 \\
\hline 1964 & 1.549 & 1.544 & 1.597 & 1.564 & 1.534 & 1.660 & 1.525 & 1.637 \\
\hline 1965 & 1.531 & 1.525 & 1.600 & 1.546 & 1.521 & 1.624 & 1.512 & 1.600 \\
\hline 1966 & 1.505 & 1.511 & 1.523 & 1.515 & 1.495 & 1.578 & 1.486 & 1.556 \\
\hline 1967 & 1.499 & 1.485 & 1.629 & 1.482 & 1.461 & 1.553 & 1.454 & 1.535 \\
\hline 1968 & 1.445 & 1.442 & 1.531 & 1.457 & 1.440 & 1.508 & 1.436 & 1.493 \\
\hline 1969 & 1.418 & 1.419 & 1.482 & 1.437 & 1.427 & 1.459 & 1.424 & 1.452 \\
\hline 1970 & 1.420 & 1.416 & 1.507 & 1.417 & 1.414 & 1.405 & 1.413 & 1.405 \\
\hline 1971 & 1.341 & 1.344 & 1.390 & 1.381 & 1.378 & 1.365 & 1.378 & 1.384 \\
\hline 1972 & 1.332 & 1.332 & 1.367 & 1.342 & 1.340 & 1.325 & 1.340 & 1.356 \\
\hline 1973 & 1.292 & 1.300 & 1.345 & 1.303 & 1.305 & 1.301 & 1.306 & 1.313 \\
\hline 1974 & 1.165 & 1.165 & 1.224 & 1.225 & 1.227 & 1.242 & 1.229 & 1.249 \\
\hline 1975 & 1.129 & 1.136 & 1.221 & 1.131 & 1.133 & 1.165 & 1.135 & 1.164 \\
\hline 1976 & 976 & 968 & 1.106 & 1.024 & 1.025 & 1.066 & 1.027 & 1.064 \\
\hline 1977 & 873 & 878 & 909 & 916 & 922 & 968 & 924 & 966 \\
\hline 1978 & 768 & 767 & 845 & 818 & 816 & 866 & 817 & 866 \\
\hline 1979 & 655 & 647 & 772 & 708 & 704 & 763 & 706 & 763 \\
\hline 1980 & 544 & 522 & 644 & 603 & 596 & 660 & 597 & 661 \\
\hline 1981 & 472 & 459 & 597 & 503 & 498 & 547 & 498 & 548 \\
\hline 1982 & 359 & 348 & 447 & 409 & 401 & 452 & 401 & 453 \\
\hline 1983 & 249 & 245 & 289 & 323 & 314 & 366 & 314 & 366 \\
\hline 1984 & 213 & 210 & I & 255 & 247 & 285 & 247 & 286 \\
\hline 1985 & 159 & 153 & i & 196 & 188 & 222 & 188 & 222 \\
\hline 1986 & 110 & 98 & i & 144 & 136 & 168 & 136 & 168 \\
\hline 1987 & 73 & 67 & I & 99 & 94 & 117 & 94 & 117 \\
\hline 1988 & I & 1 & 1 & 64 & 60 & 80 & 60 & 80 \\
\hline 1989 & 1 & 1 & 1 & 37 & 34 & 48 & 34 & 48 \\
\hline 1990 & 1 & 1 & 1 & 19 & 17 & 28 & 17 & 28 \\
\hline 1991 & 1 & 1 & 1 & 9 & 8 & 17 & 8 & 17 \\
\hline 1992 & l & i & I & 3 & 3 & 7 & 3 & 7 \\
\hline
\end{tabular}

Source: Federal Statistical Office 


\section{Comparative Population Studies - Zeitschrift für Bevölkerungswissenschaft}

wWw.comparativepopulationstudies.de

ISSN: 1869-8980 (Print) - 1869-8999 (Internet)

Published by / Herausgegeben von

Prof. Dr. Norbert F. Schneider

Layout and print: Federal Institute for Population Research, Wiesbaden

(Germany)

\section{Managing Editor / Redaktion}

Frank Swiaczny

Copy Editor / Schlußredaktion

Dr. Evelyn Grünheid

\section{Scientific Advisory Board / \\ Wissenschaftlicher Beirat}

Jürgen Dorbritz (Wiesbaden)

Paul Gans (Mannheim)

Johannes Huinink (Bremen)

Dirk J. van de Kaa (Den Haag)

Marc Luy (Wien)

Notburga Ott (Bochum)

Peter Preisendörfer (Mainz)

\section{Board of Reviewers / Gutachterbeirat}

Martin Abraham (Erlangen)

Laura Bernardi (Lausanne)

Hansjörg Bucher (Bonn)

Claudia Diehl (Göttingen)

Andreas Diekmann (Zürich)

Gabriele Doblhammer-Reiter (Rostock)

Henriette Engelhardt-Wölfler (Bamberg)

E.-Jürgen Flöthmann (Bielefeld)

Alexia Fürnkranz-Prskawetz (Wien)

Beat Fux (Zürich)

Joshua Goldstein (Rostock)

Karsten Hank (Mannheim)

Sonja Haug (Regensburg)

Franz-Josef Kemper (Berlin)

Hans-Peter Kohler (Philadelphia)

Michaela Kreyenfeld (Rostock)

Aart C. Liefbroer (Den Haag)

Kurt Lüscher (Konstanz)

Dimiter Philipov (Wien)

Tomáš Sobotka (Wien)

Heike Trappe (Rostock) 